\title{
Optimasi Penempatan Gardu Induk Menggunakan Metode Delaunay Triangulation Algorithm dan Voronoi Diagram pada Studi Kasus Jawa Timur
}

\author{
Pradipta Ghusti, Riyanarto Sarno, dan R.V. Hari Ginardi \\ Jurusan Teknik Informatika, Fakultas Teknologi Informasi, Institut Teknologi Sepuluh Nopember (ITS) \\ Jl. Arief Rahman Hakim, Surabaya 60111 Indonesia \\ e-mail: riyanarto@if.its.ac.id, hari@if.its.ac.id, pradipta.ghusti12@mhs.if.its.ac.id
}

\begin{abstract}
Abstrak-Untuk memenuhi dan mengantisipasi pertumbuhan permintaan listrik di wilayah tersebut, diperlukan penambahan gardu dan gardu pengembangan baru yang telah terjadi sebelumnya. Perusahaan Listrik Negara (PLN) mengembangkan rencana untuk menentukan jumlah, kapasitas, dan lokasi gardu untuk memenuhi kebutuhan arus listrik dengan kebutuhan listrik di masa depan. Rencana ini membutuhkan identifikasi beban listrik di setiap daerah serta pengembangan kapasitas gardu gardu yang ada. Studi ini ditunjukkan dengan menerapkan beberapa resolusi dengan menggunakan metode Delaunay Triangulation Algorithm dan Voronoi Diagram untuk membantu mencari dan menentukan lokasi gardu induk baru yang optimal. Rencana yang optimal ini, akan memenuhi kebutuhan listrik, pelayanan yang merata, dan menyesuaikan dengan kondisi masyarakat sekitar. Hasil dari studi ini mendapatkan lokasi baru sebagai tempat untuk membangun gardu induk baru sebanyak 106 titik berdasarkan implementasi dari kedua metode tersebut.
\end{abstract}

Kata Kunci-Delaunay Triangulation Algorithm, Gardu Induk, Lokasi Baru, Optimasi, Voronoi Diagram

\section{PENDAHULUAN}

$\mathrm{U}$ NTUK memenuhi dan mengantisipasi pertumbuhan kebutuhan listrik di suatu wilayah, diperlukan adanya penambahan gardu induk baru serta pengembangan gardu induk yang telah ada sebelumnya [1]. Perusahaan Listrik Negara (PLN) menyusun suatu rencana untuk menentukan jumlah, kapasitas, dan lokasi dari gardu induk guna mempertemukan kebutuhan listrik saat ini dengan kebutuhan listrik yang akan datang [2]. Rencana ini membutuhkan identifikasi beban listrik di masing-masing wilayah serta kapasitas pengembangan dari gardu-gardu induk yang sudah ada.

Beban yang dialokasikan ke suatu gardu induk, didasarkan pada jarak antar keduanya dengan mengupayakan biaya transportasi yang seminimal mungkin. Biaya tersebut didapatkan dengan menjumlahkan besar beban dengan jarak terhadap gardu induk yang melayaninya. Biaya ini teroptimasi untuk semua gardu induk melalui pengalokasian beban gardu induk yang tepat [1].

Dalam mengatasi hal-hal tersebut penulis mengajukan beberapa penyelesaian melalui studi ini dengan menerapkan metode Delaunay Triangulation Algorithm dan Voronoi Diagram untuk membantu merencanakan lokasi dari gardu induk baru secara optimal. Rencana yang optimal akan memenuhi kebutuhan jaringan listrik, pengalokasian di area yang tepat, serta memperhatikan kondisi masyarakat di sekitarnya.

\section{LITERATUR PENELITIAN}

\section{A. Voronoi Diagram}

Voronoi Diagram adalah salah satu cabang ilmu yang dipelajari dalam perkuliahan geometri komputasi yang muncul pada abad ke-17. Diagram voronoi pertama kali ditemukan oleh Rene Descartes pada tahun 1644 dan digunakan oleh Dirichlet pada tahun 1850. Kemudian Voronoi pada tahun 1907 mengembangkannya ke dalam dimensi yang lebih tinggi.

Voronoi Diagram dalam studi ini diterapkan untuk mendapatkan area layanan dari setiap lokasi gardu telah ditetapkan melalui $p$-median. Memperoleh sejumlah titik koordinat berdasarkan hasil $p$-median perhitungan $p$ titik pada bidang Euclidean [3].

$$
P=p_{1}, p_{2}, \ldots, p_{n}
$$

Semua daerah dari bidang ini terhubung dengan unsur $p$ terdekat, dengan memperhatikan jarak Euclidean. Proyeksi Voronoi Diagram pada bidang datar dapat dilihat pada Gambar 1.

Penjelasan Voronoi Diagram lebih umum adalah sebagai berikut [3]:

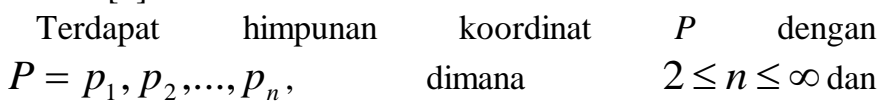
$x_{i} \neq x_{j}, i, j \in I_{n}$. Region yang didapatkan dari (1):

$$
V\left(p_{i}\right)=\left\{x /\left\|x-x_{i}\right\| \leq\left\|x-x_{j}\right\|, \text { for } j \neq i, j \in I_{n}\right\}
$$




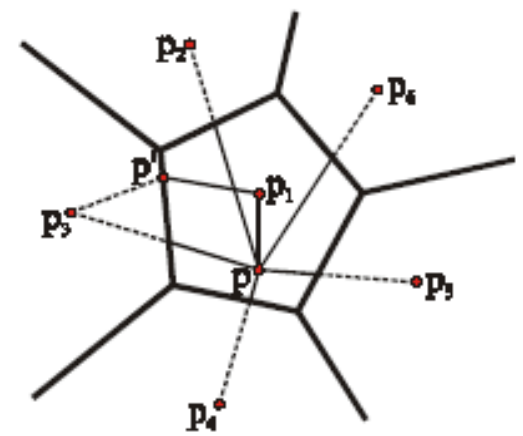

Gambar. 1. Voronoi Diagram pada bidang datar

Merupakan polygon Voronoi yang terhubung dengan $p_{i}$. Berdasarkan (2), hasil yang nantinya akan diperoleh dari himpunan $V[3]$ :

$$
V=\left\{V\left(p_{1}\right), V\left(p_{2}\right), \ldots, V\left(p_{n}\right)\right\}
$$

Pada (3), $V\left(p_{i}\right)$ merupakan himpunan dari titik-titik yang lebih dekat terhadap titik $p_{i}$ dibandingkan dengan titik $p_{i}$ lain selain $p_{i}$.

\section{B. Delaunay Triangulation Algorithm}

Delaunay merupakan algoritma yang berfokus pada segmentasi dan penggabungan, serta metode penyisipan titik per titik dari algoritma Triangulasi, algoritma yang ada pada Triangulasi sekarang hanya digunakan sedikit, algoritma segmentasi-penggabungan relarif lebih kompleks, jadi hanya menggunakan sedikit data dalam beberapa kasus penggunaannya, dan juga metode penyisipan titik per titik merupakan yang paling sederhana, yang hampir menggunakan memori sedikit saja. Tiga poin yang sesuai Voronoi polygon yang berdekatan adalah puncak pada umumnya dan ini juga termasuk vertex Delaunay Triangulasi circumcircle pusat. Voronoi polygon oleh polygon terdiri dari sekelompok yang berjalan terus menerus, batas polygon dengan menghubungkan dua segmen tetangga dari garis-garis. Delaunay Triangulasi dibagi dengan Voronoi polygon yang berdekatan tepi sambungan jalur yang relevan dari segitiga.

Delaunay titik oleh algoritma titik interpolasi untuk aturan dasar dari setiap segitiga tidak termasuk dalam circumcircle koordinat lainnya [4].

\section{Sistem Informasi Geografis}

Sistem Informasi Geografis (SIG) dapat diartikan sebagai sistem informasi yang digunakan untuk memasukkan, menyimpan, memanggil kembali, mengolah, menganalisis, dan menghasilkan data bereferensi geografis atau data geospasial, untuk mendukung pengambilan keputusan dalam perencanaan dan pengelolaan penggunaan lahan, sumber daya alam, lingkungan transportasi, fasilitas kota, dan pelayanan umum lainnya [5]-[6].

Sistem berbasis komputer yang berfungsi untuk memasukkan, menyimpan, mengolah, dan menganalisis data untuk tujuan yang berkaitan dengan pemetaan dan perencanaan.

Sistem informasi geografis juga memiliki beberapa bagian, yaitu sebagai berikut:

1. Sebuah Manipulasi Data dan Analisis

2. Data Output

3. Manajemen Data

4. Input Data

\section{Sistem Distribusi Listrik}

1) Gardu Induk

Tujuan utama dari gardu induk ialah untuk menyalurkan daya listrik bertegangan tinggi $(500 \mathrm{KV} / 150 \mathrm{KV})$ dari transmisi atau subtransmisi level, menurunkan tegangannya (dari $150 \mathrm{KV}$ menjadi $20 \mathrm{KV}$ ), kemudian menyalurkannya ke dalam beberapa tegangan primer penyulang (feeder) untuk didistribusikan ke area sekitarnya [1].

Performansi gardu induk lebih penting daripada biaya gardu induk yang diindikasikan. Gardu induk mempertemukan sistem transmisi dengan sistem distribusi, sehingga gardu induk memegang banyak peranan untuk mempengaruhi total biaya serta performansi dari kedua sistem. Perencanaan yang tepat pada level gardu induk merupakan kunci keberhasilan dari perencaanaan sistem distribusi [7].

Gardu induk merepresentasikan titik terakhir dari penyaluran sistem transmisi. Gardu induk merupakan lokasi dimana sistem transmisi harus menyalurkan daya sebesar total beban pada semua feeder yang terhubung dengan gardu induk tersebut (level distribusi).

2) Lokasi Gardu Induk, Kapasitas, dan Area Pelayanan

Listrik yang disalurkan ke setiap konsumen berasal dari gardu induk yang terletak berdekatan dengan konsumen atau bisa saja berasal dari tempat lain yang lebih jauh [8]. Teritorial service area listrik dibagi menjadi beberapa service area gardu induk, seperti yang digambarkan pada Gambar 2 di bawah ini.

Setiap gardu induk (dilambangkan sebagai kotak kecil) yang melayani area tertentu (batas-batas garis pada gambar) harus memiliki kapasitas yang cukup untuk melayani maximum demand dari semua konsumen yang ada di area tersebut [7].

Untuk industri konsumen, beban yang diperlukan tentu akan lebih besar jika dibandingkan dengan konsumen rumah tangga, sehingga dua area layanan identik, beban total belum tentu sama.

Service area dalam hal ini berupa titik-titik beban yang tersebar di sekitar gardu induk. Titik beban tersebut merupakan titik demand dari konsumen yang belom tentu sama antar satu konsumen dengan konsumen di daerah yang lain, bergantung pada karakteristik masing-masing konsumen. Untuk konsumen pada sektor industri, beban yang dibutuhkan tentunya akan lebih besar bila dibandingkan dengan konsumen dari sektor rumah tangga. Sehingga untuk dua service area yang identik, belum tentu total bebannya sama [7].

Penambahan gardu baru akan dilakukan ketika kapasitas gardu-gardu di daerah (sudah pra-install) tidak mampu memenuhi permintaan konsumen. Dengan demikian, harus ada penambahan gardu baru sebanyak mungkin untuk mengatasi gardu kelebihan beban. 


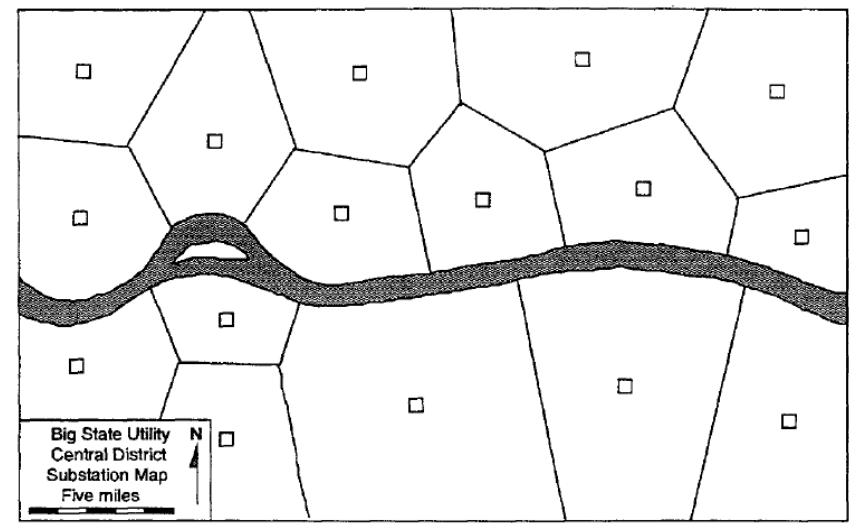

Gambar. 2. Layanan wilayah divisi berbasis lokasi gardu induk

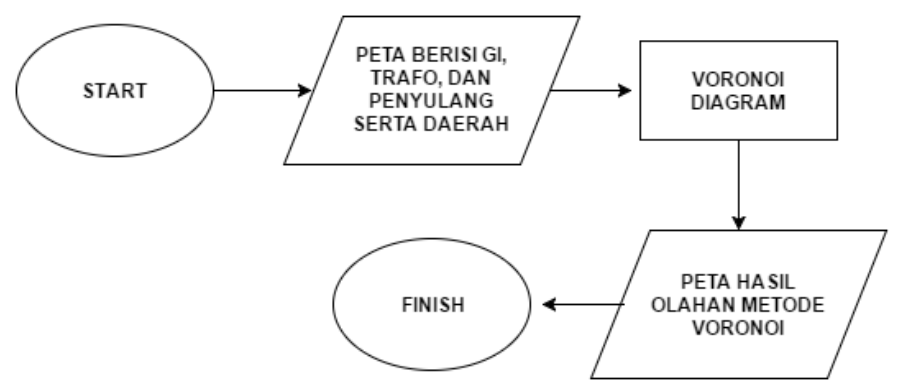

Gambar. 3. Diagram alur memodelkan Voronoi Diagram

\section{3) Pusat Titik Beban}

Cara terbaik agar gardu induk dapat melayani konsumen secara maksimal tetapi dengan biaya yang minimal adalah dengan meletakkan gardu induk di pusat service area atau pusat beban. Berikut adalah cara menentukan letak gardu induk dengan mempertimbangkan gardu induk lain yang telah terpasang sebelumnya [7]:

1. Menggambar garis lurus antara rencana letak gardu induk baru dengan tiap gardu induk yang berdekatan.

2. Menarik garis tegak lurus di setiap garis tersebut (membagi garis pada langkah 1 menjadi dua bagian dengan sudut sikusiku).

3. Garis-garis yang dihasilkan pada langkah 2 dan saling berpotongan, menunjukkan service area dari gardu induk baru.

4. Target beban (kapasitas) yang akan dipasangkan di gardu induk baru adalah total dari beban di sekitar service area.

\section{PERANCANGAN SISTEM}

\section{A. Memodelkan Voronoi Diagram pada ArcMap 10.3}

Dalam ArcMap memodelkan sebuah metode tidak bisa langsung memproses dengan data, harus ada sebuah tools yang berisi script yang mengandung metode. Tools tersebut dalam aplikasi ArcMap dibungkus menjadi satu dengan nama Toolbox. Dalam Toolbox dapat menampung lebih dari satu function atau metode, tetapi hanya dapat digunakan dalam bahasa pemrograman Python. Metode Voronoi Diagram di sini digunakan untuk menentukan service area yang ditentukan dari titik vertices penyulang dari setiap APJ. Desain proses sistem dapat dilihat pada Gambar 3.

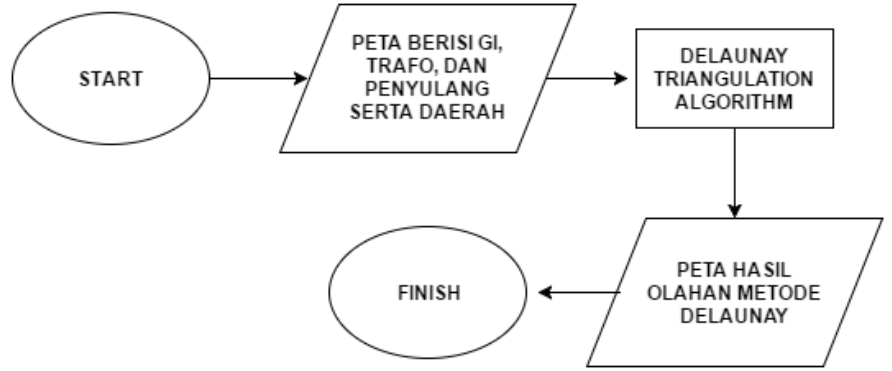

Gambar. 4. Diagram alur memodelkan Delaunay Triangulation Algorithm

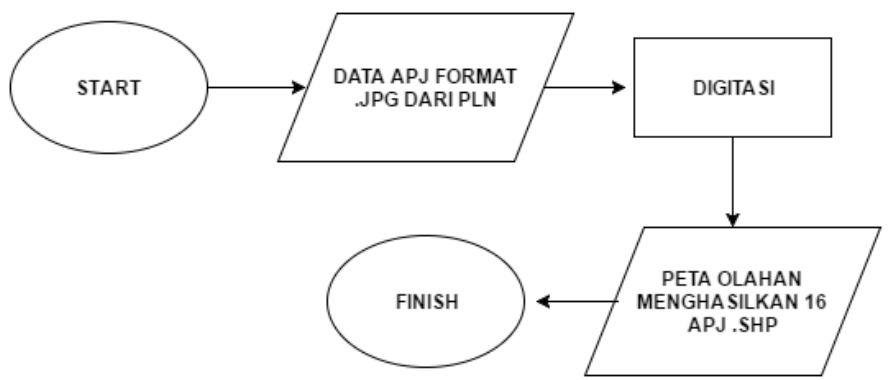

Gambar. 5. Diagram alur implementasi APJ

\section{B. Memodelkan Delaunay Triangulation Algorithm pada} ArcMap 10.3

Kemudian diimplementasikan metode Delaunay Triangulation Algorithm agar mendapatkan jaringan distribusi listrik dan service area yang optimal. Metode ini dijalankan diatas metode Voronoi Diagram yang sebelumnya sudah diimplementasikan, dengan menggunakan titik vertices dari penyulang (feeder) juga. Output dari metode ini adalah sebuah garis yang membentuk segitiga dari titik vertices. Desain proses sistem dapat dilihat pada Gambar 4.

\section{Mengimplementasi Area Pelayanan Jaringan Sesuai dengan Data dari PLN}

Dalam usaha untuk memperlihatkan hasil yang maksimal sesuai dengan keadaan yang dimiliki oleh PLN (Perusahaan Listrik Negara), penulis membuat daerah per APJ dengan cara digitization berdasarkan data yang asli. Kemudian menghasilkan peta berformat .shp yang berisi daerah-daerah per APJ. Desain proses sistem dapat dilihat pada Gambar 5.

\section{Mengimplementasi Dua Metode dengan Data yang Sudah} Ada

Setelah metode telah disatukan dalam toolbox, daerah per APJ terbentuk dan titik gardu induk serta penyulang sudah diaplikasikan, maka langkah berikutnya adalah mengimplementasikan kedua metode dengan data yang sudah ada. Kedua metode tersebut Voronoi Diagram dan Delaunay Triangulation Algorithm memproses data berupa titik penyulang agar membuat sebuah service area serta jaringan distribusi listik yang nantinya akan dijadikan parameter untuk menentukan lokasi gardu induk yang baru. Desain proses sistem dapat dilihat pada Gambar 6.

\section{E. Memodelkan Bukti Kemiripan dengan Data PLN}

Dalam usaha dalam memperlihatkan hasil implementasi yang telah dilakukan oleh penulis berupa titik lokasi baru dari gardu induk, disini dilakukan percobaan membandingkan dengan hasil yang telah direncanakan oleh PLN. Cara membandingkannya 
adalah dengan cara meng-overlay peta yang didapatkan dari PLN dengan peta hasil olahan yang diimplementasi oleh penulis. Berikut langkah-langkah prosesnya dijelaskan dalam Gambar 7.

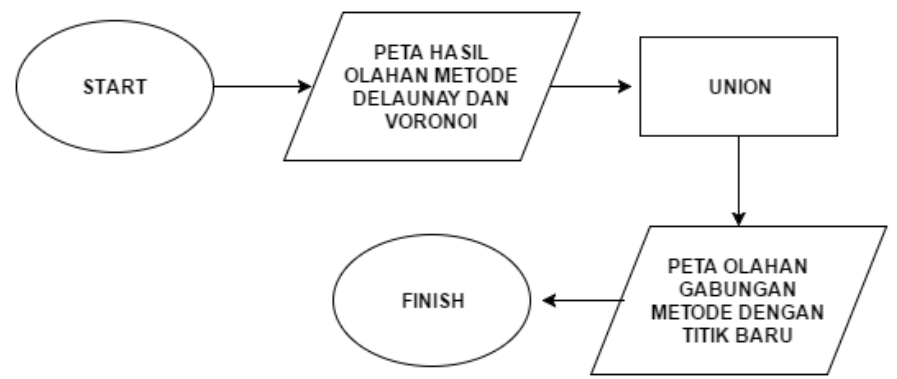

Gambar. 6. Diagram alur implementasi dua metode

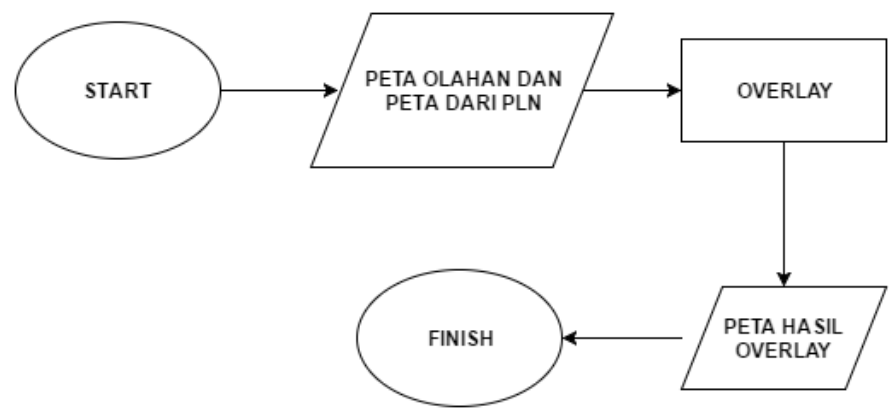

Gambar. 7. Diagram alur bukti kemiripan dengan data PLN

\section{IMPLEMENTASI}

\section{A. Implementasi Area Pelayanan Jaringan (APJ)}

Pada tahap ini membahas bagaimana membangun Area Pelayanan Jaringan (APJ) sesuai dengan data yang didapatkan dari PLN Distribusi Jawa Timur. Dikarenakan file yang didapatkan berformat .cdr (format file pada aplikasi Corel Draw), maka diharuskan meng-export terlebih dahulu ke format .jpg. Berikut ini adalah langkah dan implementasi Area Pelayanan Jaringan menggunakan ArcMap:

1. Buka aplikasi ArcMap lalu add data kemudian add data raster yang ingin didigitasi.

2. Dari ArcCatalog buat sebuah shapefile, klik kanan pada folder lalu new kemudian shapefile.

3. Tentukan nama file, tipe data, dan titik koordinat dari file .shp. Buat titik penanda berupa point, polyline untuk garis dan polygon untuk daerah lalu ok.

4. Setelah file .shp sudah terbuka di table of content, dari main menu Editor lalu Start Editing.

5. Mulai proses digitasi dengan hati-hati dan rapih.

6. Setelah selesai, klik kanan pilih finish. Hasil implementasi APJ dapat dilihat pada Gambar 8 .

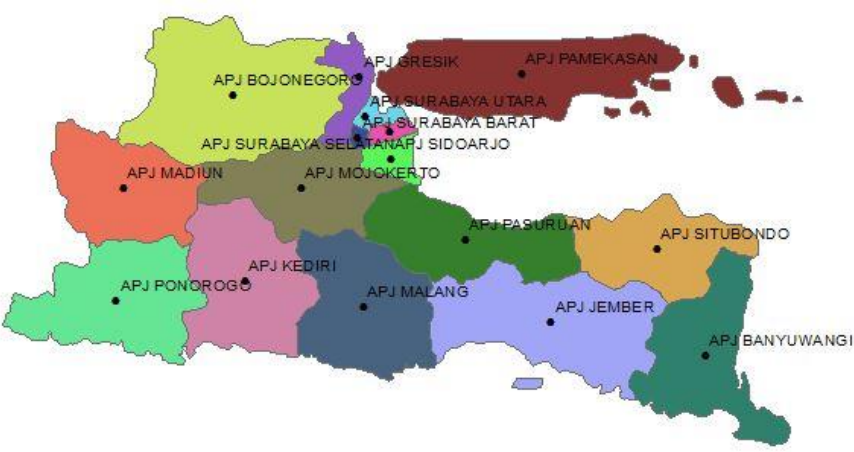

Gambar. 8. Hasil implementasi APJ di Jawa Timur

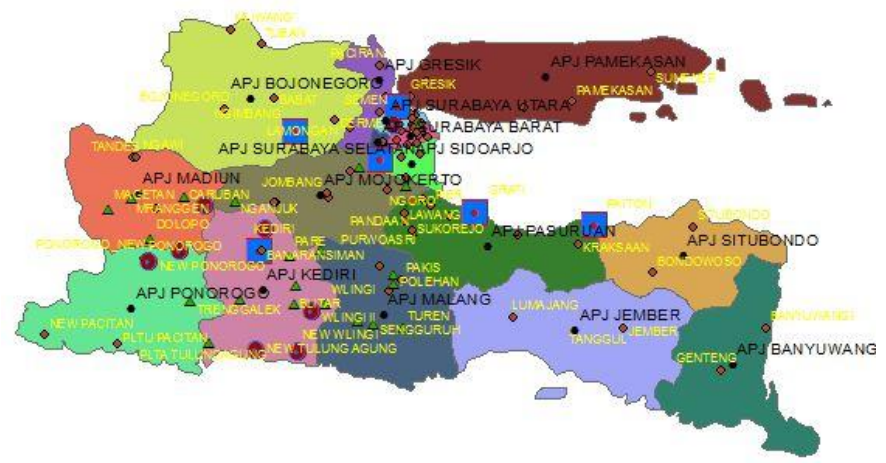

Gambar. 9. Lokasi yang sudah ditentukan dengan koordinat

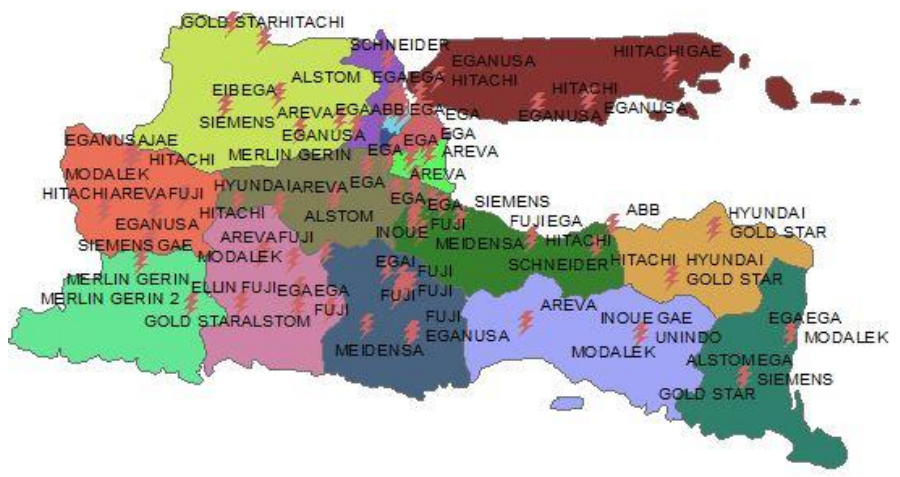

Gambar. 10. Proyeksi trafo existence pada peta APJ

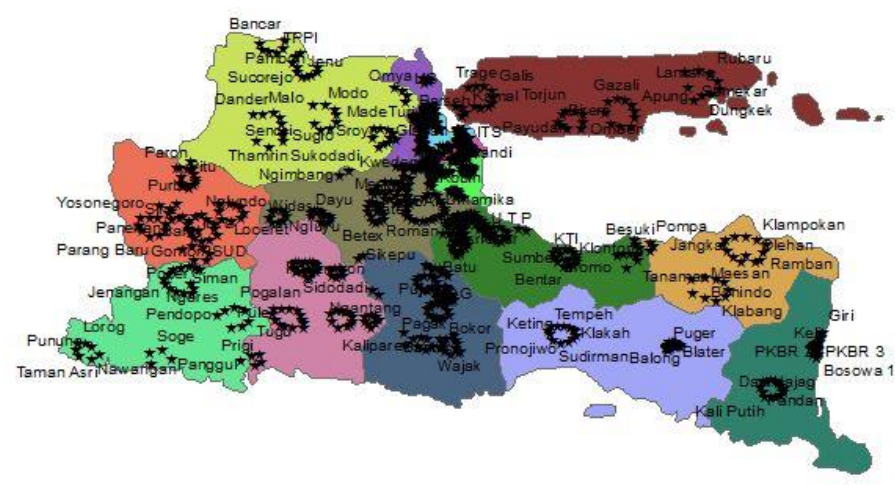

Gambar. 11. Proyeksi penyulang existence pada peta APJ 


\section{B. Implementasi Proyeksi Gardu Induk Existence di ArcMap 10.3}

Pada tahap ini akan ditunjukkan bagaimana memproyeksikan gardu induk existence pada peta APJ yang sebelumnya sudah di digitasi. Berikut langkah-langkah yang dilakukan agar dapat menampilkan gardu induk yang sudah ada:

1. Buka atribut data tabel yang ingin dihitung geometrinya.

2. Tambahkan kolom baru pada atribut tabel untuk mengisi koordinat $\mathrm{x}$ dan $\mathrm{y}$.

Kemudian klik kanan pada kolom baru tersebut lalu calculate geometry. Hasilnya akan ditunjukkan pada Gambar 9.

\section{Implementasi Proyeksi Trafo dan Penyulang di ArcMap}

Pada tahap ini akan ditunjukkan bagaimana memproyeksikan trafo dan penyulang yang existence, berikut langkah-langkah yang dilakukan agar dapat menampilkan trafo dan penyulang yang sudah ada:

1. Buka atribut data tabel yang ingin dihitung geometrinya.

2. Tambahkan kolom baru pada atribut tabel untuk mengisi koordinat $\mathrm{x}$ dan $\mathrm{y}$.

Kemudian klik kanan pada kolom baru tersebut lalu calculate geometry. Hasilnya akan ditunjukkan pada Gambar 10 dan Gambar 11.

\section{Implementasi Metode Voronoi Diagram}

Pada tahap ini, penulis akan menjelaskan kenapa menggunakan metode Voronoi Diagram. Metode ini digunakan untuk mendapatkan service area dari setiap daerah yang belum tercakupi oleh service area tersebut diasumsikan sebagai daerah yang belum terpenuhi kebutuhan listriknya atau bahkan belum mendapatkan listrik sama sekali, dan hal ini memungkinkan untuk membangun gardu induk yang baru di daerah tersebut.

Untuk membuat metode ini mudah diimplementasikan dan digunakan dalam aplikasi ArcMap, digunakan sebuah alat bantu berupa tools yang bernama toolbox. Toolbox ini berfungsi untuk memanggil secara langsung metode yang terkandung didalamnya. Toolbox ini hanya dapat menyimpan metode dan fungsi script berisi syntax dengan bahasa pemrograman Python. Berikut hasil output olahan metode Voronoi Diagram yang dihasilkan, hasil implementasinya dapat dilihat pada Gambar 12.

\section{E. Implementasi Metode Delaunay Triangulation Algorithm}

Pada tahap ini, penulis menjelaskan bagaimana menggunakan metode Delaunay Triangulation Algorithm. Metode ini digunakan untuk mendapatkan jaringan distribusi listrik dari setiap penyulang (feeder) yang sudah aktif dan terpasang sebelumnya. Hasil yang didapatkan, diketahui bahwa daerah mana saja yang belum tercakupi oleh jaringan distribusi listrik. Daerah-daerah mana yang belum tercakupi oleh jaringan distribusi listrik tersebut diasumsikan sebagai daerah yang belum terpenuhi kebutuhan listriknya atau bahkan belum mendapatkan listrik sama sekali, dan hal ini memungkinkan untuk membangun gardu induk yang baru di daerah tersebut.

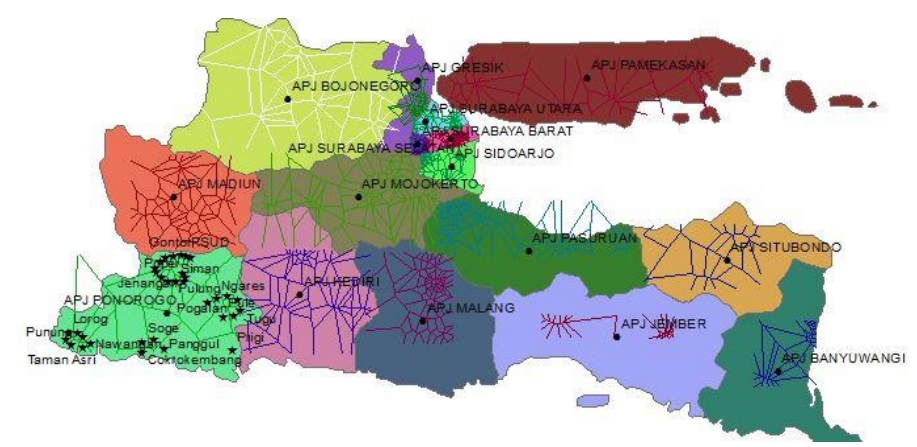

Gambar. 12. Implementasi Voronoi Diagram terhadap penyulang

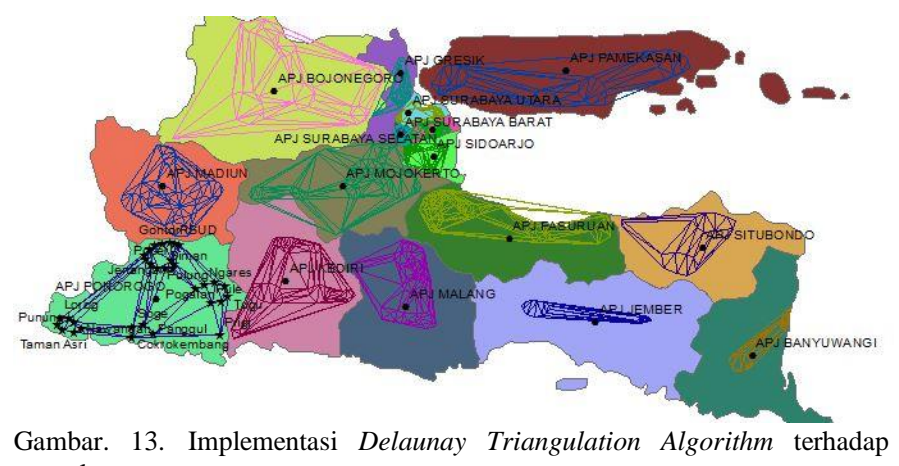
penyulang

Hal yang sama pada tahap sebelumnya, untuk membuat metode ini mudah diimplementasikan dan digunakan dalam aplikasi ArcMap, digunakan sebuah alat bantu berupa tools yang bernama toolbox. Toolbox ini berfungsi untuk memanggil secara langsung metode yang terkandung didalamnya. Toolbox ini hanya dapat menyimpan metode dan fungsi script berisi syntax dengan bahasa pemrograman Python. Hasil implementasi dapat dilihat pada Gambar 13.

\section{F. Implementasi Penerapan Dua Metode pada Data Gardu} Induk, Trafo, dan Penyulang

Pada tahap ini dijelaskan bagaimana kedua metode yang sudah diimplementasikan sebelumnya, digabungkan menjadi satu untuk mendapatkan daerah yang belum tercakupi oleh service area dan jaringan distribusi listrik. Daerah ini merupakan daerah yang paling optimal, karena di daerah tersebut diasumsikan sebagai daerah yang tidak memiliki kedua parameter seperti service area dan jaringan distribusi listrik. Berikut merupakan hasil implementasi kedua metode pada peta APJ (Area Pelayanan Jaringan), dapat dilihat pada Gambar 14.

\section{G. Implementasi Titik Baru Disesuaikan dengan Data Parameter}

Pada tahap ini dijelaskan bagaimana mendapatkan titik baru untuk pembangunan gardu induk baru. Setelah mendapatkan daerah yang belum terpenuhi akan kebutuhan listriknya yang didapat dari dua metode, yaitu Voronoi Diagram dan Delaunay Triangulation Algorithm, maka penulis mendapatkan titik-titik baru yang disimbolkan dengan bendera kuning pada peta sebanyak 106 titik. Hasil tersebut dapat dilihat pada Gambar 15. 


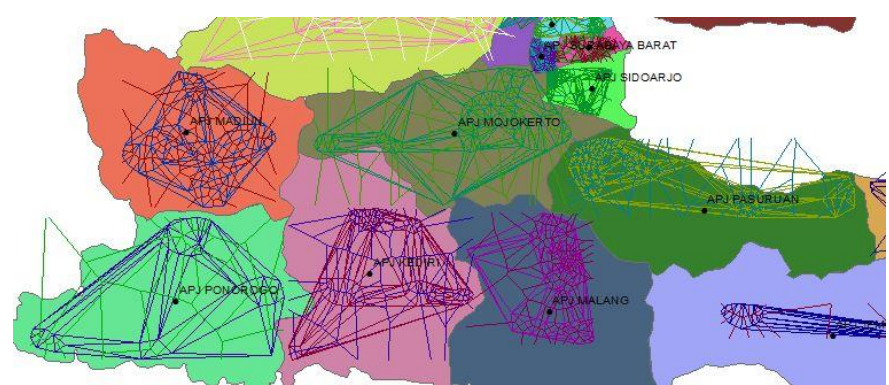

Gambar. 14. Hasil penggabungan dua metode

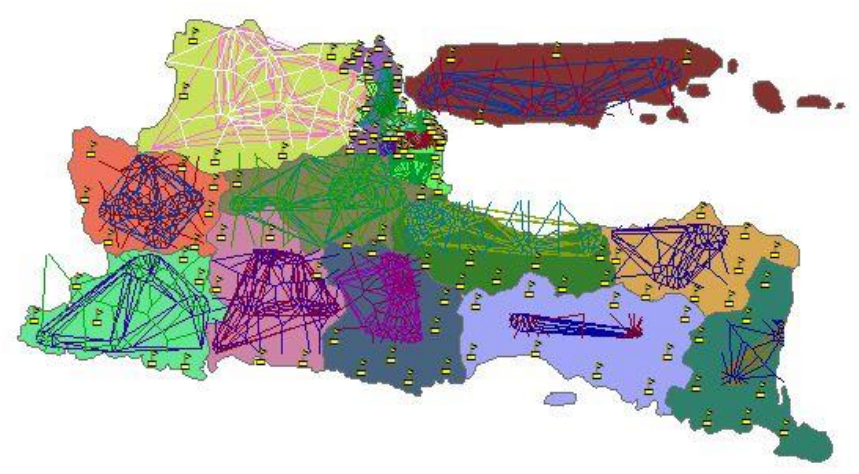

Gambar. 15. Lokasi dari titik baru

\section{KESIMPULAN}

Berdasarkan hasil studi yang telah dilakukan, dapat diambil beberapa kesimpulan sebagai berikut:

a. Menghasilkan titik-titik gardu induk baru yang optimal sebanyak 81 titik yang tersebar di semua wilayah APJ di Jawa Timur sesuai dengan letak geografisnya menggunakan metode Voronoi Diagram dan Delaunay Triangulation Algorithm.

b. Dapat memetakan beban gardu induk dengan menggunakan metode Voronoi Diagram per daerah APJ (Area Pelayanan Jaringan) sesuai dengan kebutuhan listrik daerahnya masingmasing.

c. Dapat memetakan menjadi ke 16 daerah wilayah APJ (Area Wilayah Jaringan) menggunakan teknik digitasi pada ArcGIS berdasarkan data PLN.

d. Terdapat kesamaan dalam penempatan lokasi titik gardu induk baru sesuai dengan perencanaan yang dilakukan oleh PLN, yaitu sebanyak 6 lokasi titik yang sama dari 8 lokasi yang telah direncanakan.

Titik gardu induk baru yang ditemukan diperkirakan dapat memenuhi kebutuhan listrik di Jawa Timur sampai dengan tahun 2028.

\section{DAFTAR PUSTAKA}

[1] R. Sarno and N. F. Ariyani, "Optimasi Penempatan Gardu Induk Menggunakan Metode P-Median dan Voronoi Diagram," Jurusan Teknik Informatika, ITS, Surabaya, 2008.

[2] A. D. Purwanto, U. Subchan and I. G. N. Rai, "Fuzzy Clustering untuk Optimasi Perencanaan Letak Unit Pembangkit Listrik di Jawa Timur," in Seminar Tugas Akhir, ITS, Surabaya, 2013.

[3] H. S. Lopes, G. C. Correa, L. C. Galvao and L. F. Nunes, "Optimized Electric Power Substation Location Using P-Medians and Voronoi Diagrams," in The XXVI Iberian Latin-American Congress on
Computational Methods, Electronics Department, Centro Federal de Educação Tecnológica do Paraná, Brazillia, 2005.

[4] V. J. Tsai, "Fast Topological Construction of Delaunay Triangulation and Voronoi Diagram," Department of Civil and Environmental Engineering, U.S.A, 1993.

[5] S. M. Castongia, "A Demand-Based Resource Allocation Method For Electrical Substation Service Area Delineation," Department of Geography and Earth Sciences, Charlotte, 2006.

[6] R. Sarno, U. L. Yuhana and P. Wardana, "Rancang Bangun Sistem Informasi Geografis Pengelolaan Perizinann Reklame Studi Kasus Kota Malang," in Digital Information and System Conference, Jurusan Teknik Informatika ITS, Surabaya, 2009.

[7] R. Sarno and N. F. Ariyani, "Design and Implementation of P-Median Method For Locating Electric Power Subtation," in International Conference on Computer, Control, Informatics and its Applications, Informatics Engineering, ITS, Surabaya, 2009.

[8] S.-W. Lee, W. J. Tolone and W.-N. Xiang, "A Feasibility Study of Substation Service Area Estimation Methodologies," Department of Geography and Earth Sciences, Charlotte, 2006. 